\title{
Pathophysiological mechanisms of root resorption after dental trauma: a systematic scoping review
}

\author{
Kerstin M. Galler ${ }^{1 *}$, Eva-Maria Grätz ${ }^{1}$, Matthias Widbiller ${ }^{1}$, Wolfgang Buchalla ${ }^{1}$ and Helge Knüttel²]
}

\begin{abstract}
Background: The objective of this scoping review was to systematically explore the current knowledge of cellular and molecular processes that drive and control trauma-associated root resorption, to identify research gaps and to provide a basis for improved prevention and therapy.

Methods: Four major bibliographic databases were searched according to the research question up to February 2021 and supplemented manually. Reports on physiologic, histologic, anatomic and clinical aspects of root resorption following dental trauma were included. Duplicates were removed, the collected material was screened by title/abstract and assessed for eligibility based on the full text. Relevant aspects were extracted, organized and summarized.

Results: 846 papers were identified as relevant for a qualitative summary. Consideration of pathophysiological mechanisms concerning trauma-related root resorption in the literature is sparse. Whereas some forms of resorption have been explored thoroughly, the etiology of others, particularly invasive cervical resorption, is still under debate, resulting in inadequate diagnostics and heterogeneous clinical recommendations. Effective therapies for progressive replacement resorptions have not been established. Whereas the discovery of the RANKL/RANK/OPG system is essential to our understanding of resorptive processes, many questions regarding the functional regulation of osteo- $/$ odontoclasts remain unanswered.
\end{abstract}

Conclusions: This scoping review provides an overview of existing evidence, but also identifies knowledge gaps that need to be addressed by continued laboratory and clinical research.

Keywords: Root resorption, Tooth resorption, Osteoclast, Receptor activator of nuclear factor-kappa B, RANK ligand, Osteoprotegerin

\section{Background}

Dental trauma presents in countless individual forms and characteristics. The broad spectrum of injury patterns is a consequence of the multiple possible combinations of damage to gingiva, dental hard tissues, pulp,

\footnotetext{
${ }^{*}$ Correspondence: kerstin.galler@klinik.uni-regensburg.de

1 Department of Conservative Dentistry and Periodontology, University Hospital Regensburg, Franz-Josef-Strauß Allee 11, 93053 Regensburg, Germany

Full list of author information is available at the end of the article
}

periodontium and alveolar bone [1]. This complexity contributes to an increased incidence of long-term consequences, where combined injuries may cause late effects in $65 \%$ of all cases [2-4]. Dental trauma is problematic especially in children, where tooth development and growth of the jaw bones are incomplete, and low compliance may complicate adequate therapies [5]. Not all oral tissues contribute equally to late effects: whereas gingiva and bone heal within days to weeks, damage to dental pulp and periodontal tissues are determinants for 
poor long-term prognosis of traumatized teeth [6]. Complex healing processes take place to repair or regenerate damaged structures, but pulp necrosis or destruction of periodontal tissue architecture may occur. Whereas pulp necrosis can usually be treated without much difficulty, extensive damage to the periodontium is irrepairable. Thus, recent approaches in dental traumatology primarily explore anti-resorptive and regenerative therapies to preserve periodontal tissues [6]. Damage to pulp and periodontium may result in root resorption, a pathological process characterized by progressive loss of cementum and dentine due to clastic cellular activity [7]. Whereas resorptive processes in bone are mostly physiological as a constant turn-over and adaptive response to stress and stimulation [8], teeth are not subjected to physiological remodeling apart from resorption in deciduous teeth. Permanent teeth are protected from resorption by barriers, on the root surface by a layer of cementum, within the endodontium by a layer of predentine $[9,10]$. Damage to these protective layers, e.g. after dental trauma, exposes the underlying dentine and makes it accessible to clastic cells [10], which can bind exclusively to mineralized tissue surfaces to initiate the resorptive process [1113]. A recent investigation among adolescents reported a risk of root resorption after dental trauma to be $2.3 \%$ [14].

Different classifications of root resorptions can be found in the literature based on etiological aspects or stimulatory factors [15-18], but more commonly based on their anatomic location in relation to the root surface $[19,20]$. The prognosis of teeth with root resorption is questionable, without therapeutic intervention poor. Root resorption after dental trauma in the permanent dentition remains a challenge to the dental practitioner, due to manifold etiology and diverse clinical appearance. To ensure prevention or early detection and optimal treatment, it is essential to understand the underlying pathophysiological processes. The aim of this scoping review was to extract all available information on the regulation and pathogenesis of root resorption from the literature, to identify knowledge gaps, to compile a concise overview and thus contribute to a better understanding of the disease patterns.

\section{Methods}

Protocol

The form of a scoping review was chosen as this type of review offers an innovative tool to delineate a broad research question in a systematic way and thus allows for an assessment of valid knowledge, knowledge gaps and the needs for future research [21]. The protocol was not prospectively published or registered with PROSPERO (International prospective register of systematic reviews) [22] as the focus of this study on basic science and the more explorative nature of this scoping review do not quite fit PROSPERO's objectives aiming towards outcomes of direct patient or clinical relevance. In addition, PROSPERO denied registration of scoping reviews or literature scans at the time the study was conducted. This work was initially aligned to the applicable aspects of PRISMA [23]. As soon as the PRISMA extension for Scoping Reviews (PRISMA-ScR) became available, which better suited the needs for this study, the format was adapted [24]. A checklist of the preferred items according to PRISMA-ScR can be found in Additional file 1.

\section{Literature search and data management}

The search included reports on clinical aspects and pathophysiological mechanisms of root resorption after dental trauma in the bibliographic databases listed in Table 1. The last search update was run on February 9th, 2021. The search strategies were based on the two concepts "dental trauma" and "root resorption" which were combined with the Boolean operator "AND". No limits or search filters were applied. A medical librarian (HK) developed the search strategies in close cooperation with

Table 1 Data bases for electronic literature search

\begin{tabular}{llc}
\hline Name of database & Provider/interface & Time period covered \\
\hline Embase & Ovid & $1974-2021$ \\
MEDLINE & Ovid & $1950-2021$ \\
Cochrane Library & Wiley Online Library & $1995-2021$ \\
Cochrane Database of Systematic Reviews (CDRS) & Wiley Online Library & $1948-2021$ \\
Cochrane Central Register of Controlled Trials (CENTRAL) & Wiley Online Library & $1995-2015$ \\
Database of Abstracts of Reviews of Effect (DARE) & Wiley Online Library & $1994-2015$ \\
NHS Economic Evaluation Database & Wiley Online Library & $1988-2015$ \\
Health Technology Assessment Database (HTA) & Web of Science & $1965-2021$ \\
Science Citation Index Expanded & &
\end{tabular}


the domain experts. For each of the concepts, a broad range of synonyms and relevant subject terms from the databases' thesauri was compiled. While the search strategy was not peer-reviewed, the study was conducted in adherence to the PRESS checklist [25]. The full electronic search strategies that allow for replication of searches can be found in Additional file 2 .

The database searches were complemented by manual searches. To amplify the search, the reference lists of the books and articles considered as most relevant were screened. When reviewing other texts, the full texts of references considered as potentially relevant were checked, as well as articles specified as recommended reading. This was amended by ad hoc searches in Google Scholar for specific aspects. Records from the searches were transferred to a reference manager software (Citavi 6, Swiss Academic Software GmbH, Wädenswil, Switzerland) for deduplication, title/abstract screening and subsequent study selection based on the full text.

\section{Eligibility criteria}

While we employed no language filter in the database searches, manuscripts selected for review were limited to English and German language in order to cope with the large number of results (Table 2). Papers unrelated to pathophysiology of resorption in bone and teeth, unrelated to dental traumatology or related to implant prosthetics or veterinary medicine were excluded. Orthodontically induced root resorptions were not excluded a priori but excluded if unrelated to pathophysiological mechanisms. Clinical cases of dental trauma unrelated to root resorption were excluded as well as papers that clearly were no longer up to date, had been published repeatedly or had successors. Included were papers containing physiologic, histologic, anatomic and clinical aspects of root resorption as well as publications that were not primarily focused on trauma-induced root resorption but reported detailed insights into resorptive processes in general. Thus, numerous studies on orthodontically induced root resorption or resorption in deciduous teeth were included, along with material on the biology, physiology and histology of bone.

\section{Data extraction and qualitative synthesis}

Information was extracted from the articles identified as relevant after thorough inspection and sorted into the following categories based on their primary content: (1) anatomy and histology, (2) regulation and pathogenesis and (3) etiology. During this process, the outline of this manuscript was refined and complemented. Controversial statements and unsettled issues were identified and are pointed out in the results section. Numerous publications appeared to be similar regarding content and referenced sources. In that case, findings were reported while citing only representative works. The results section comprises the information extracted from all included articles in a compacted summary.

\section{Results}

The electronic and manual searches yielded 7513 records, 4139 remained after removal of duplicates to be subsequently screened for relevance on the basis of title and abstract. After screening, 2490 were excluded as nonrelevant. The remaining 1649 full texts were reviewed for eligibility, and 803 were removed due to the exclusion criteria. Finally, 846 full text reports were summarized qualitatively. The process is illustrated in the PRISMA flowchart in Fig. 1 [23]. Many of the eligible articles contained identical or similar information in respect to the purpose of this study. Therefore, only representative sources were cited. Systematic reviews were found mainly on orthodontically-induced root resorption, reviews on trauma-induced resorption are scarce and do not focus on pathophysiological aspects.

\section{Physiological and pathological resorption in bone and the RANKL/RANK/OPG system}

In bone, continuous remodeling enables functionality; it is essential during growth and for adaptation to everchanging mechanical stresses $[9,26] .10 \%$ of the total bone mass is exchanged annually, where bone remodeling

Table 2 Eligibility criteria

\begin{tabular}{ll}
\hline Inclusion & Exclusion \\
\hline $\begin{array}{l}\text { English and German language } \\
\begin{array}{l}\text { Content of physiologic, histologic, anatomic and clinical } \\
\text { aspects of root resorption }\end{array}\end{array}$ & $\begin{array}{l}\text { No relation to pathophysiology of resorption in bone and teeth or dental traumatology } \\
\text { Relation to imt prosthetics or veterinary medicine }\end{array}$ \\
& $\begin{array}{l}\text { Orthodontically induced root resorptions if no relation to pathophysiological mechanisms } \\
\text { Clinical cases of dental trauma without relation to root resorption }\end{array}$ \\
& Papers published or updated multiple times \\
\hline
\end{tabular}




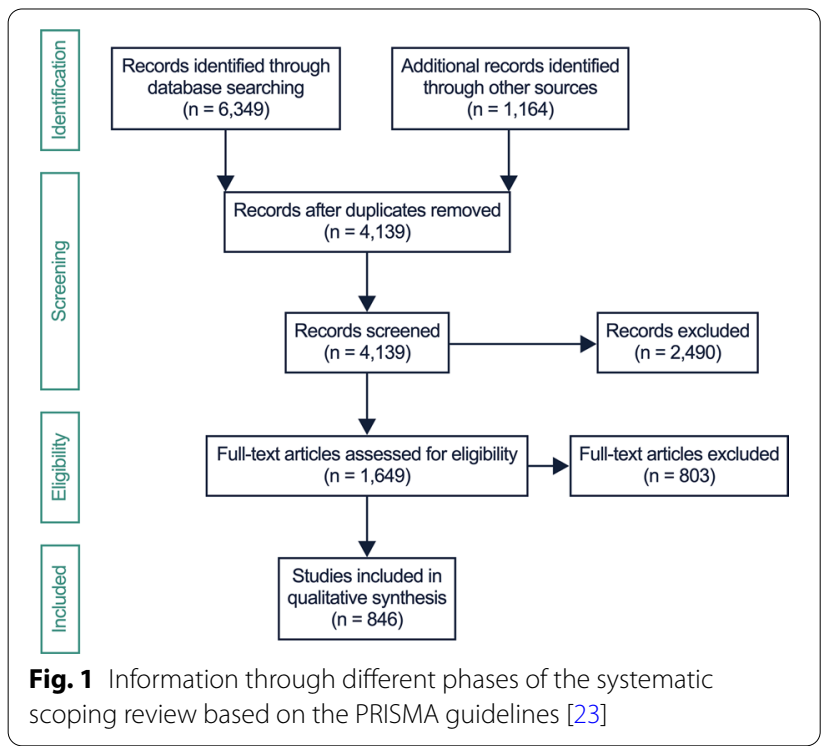

prevents material fatigue and enables the repair of microtrauma, along with the efficient mobilization of calcium [27]. This process is a quantitatively, spatially and temporally tightly regulated interplay of osteoclasts and osteoblasts $[9,11,28]$. Under physiological conditions, there is an equilibrium of bone formation and resorption, which is achieved through a finely tuned interaction of both processes called "coupling" [29]. A pathologic imbalance of this dynamic remodeling can lead to alterations of bone structure and stability [30].

The receptor-ligand system RANKL/RANK/OPG plays an essential role, these proteins of the TNF-family are key molecules regulating physiological and pathological resorption of mineralized tissues [31-34]. They control all aspects of osteoclast function $[35,36]$ and regulate the communication between bone cells and vascular as well as immune cells [37].

RANKL is expressed by osteoblasts either as membrane-bound or soluble protein [37]. Osteoclasts, their mononuclear precursors as well as dendritic cells carry the respective receptor called RANK $[38,39]$. Binding of RANKL to RANK starts signal transduction via the transcription factor NF- $\mathrm{kB}$, induces fusion of osteoclast precursors into multi-nucleated cells and thus stimulates their maturation (Fig. 2) [40-43]. Soluble OPG competitively binds to RANKL and efficiently inhibits osteoclast formation and thus bone resorption [44]. Local and systemic factors influence this process [45]. Bone resorption and calcium release are stimulated by inflammatory cytokines or PTH, estrogen and calcitonin have the opposite effect [46, 47]. Progressive resorption due to elevated clastic activity is characteristic of diseases such as rheumatoid arthritis [48], osteoporosis

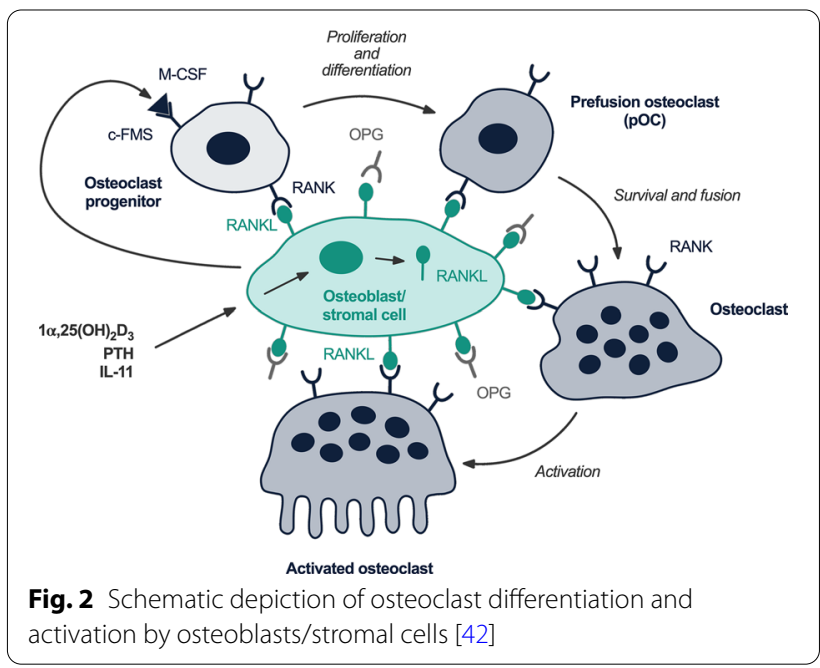

[49] or periodontal disease [50]. Activation of immune cells leads to the release of cytokines like TNF $\alpha$, which induces a complex inflammatory cascade characterized by increased cell differentiation, activation of osteoclasts and inhibition of apoptosis [34, 51, 52]. In periodontal disease, the cytokines IL-1, TNF $\alpha$ und IL- 6 activate osteoclasts via RANKL, resulting in increased resorption of the alveolar bone.

\section{Etiological factors of root resorption}

The development of any type of root resorption is tied to two premises: an initial injury and the subsequent persistence of a stimulus [15-17]. The injury damages the protective layer of root dentine [53]. Cementoblasts are destroyed directly or become necrotic as a result of a compromised blood supply to the periodontal ligament or dental pulp [54]. The lesion can be induced by trauma, surgical procedures or periodontal treatment [53], by pressure caused by impacted teeth, cysts or tumors [12, $55]$, or chemically by caustic compounds such as hydrogen peroxide used for internal bleaching [56]. Increased tissue pressure is also generated during orthodontic treatment, where complications such as apical root resorption can lead to significant root shortening [57]. Excessive occlusal load can promote resorption [58], but interestingly also the absence of physiological stresses in the case of orthodontic movement in non-occlusion [59]. Furthermore, infections of the root canal or periodontal ligament may trigger resorption [18].

Only a few systemic and endocrine diseases involve root resorption, which shows again that teeth provide a remarkable resistance to resorption. Links have been observed for hypo- as well as hyperparathyroidism, calcinosis, Gaucher's disease, Turner syndrome, Paget's disease and Herpes zoster [18]. Root resorption due to 
systemic disease can be found most commonly bilaterally and at the root apex. Resorptions are termed idiopathic if no local or systemic factors can be identified, however, there are only few reports in the literature. Idiopathic resorptions were found in single or multiple teeth, did not cause symptoms, and were incidental radiographic findings [60]. A cervical type progressing towards the pulp has been distinguished from an apical type, which progresses towards the coronal aspect of the tooth, causing successive root shortening [61].

\section{Types of root resorption}

The type of resorption which develops depends on the type and intensity of the initial injury, the stage of root development and on the pulpal status [62]. Whereas the initial injury may be similar for different types of resorption, the subsequently dominating stimulus, which clastic cells depend on during phagocytosis [63], is decisive for further progression. Without a constant stimulus, the resorptive process is self-limiting and will arrest within 2-3 weeks [64]. This explains the phenomenon of transient resorption, which occurs to varying degree after minor traumatic impact and stops spontaneously without therapeutic intervention [15, 65]. Small and localized damage to root cementum can regenerate after a transient, self-limiting process, where neighboring intact cementoblasts repair the defect [15].

Severe damage to cementum affecting more than $20 \%$ of the root surface leads to extensive cell necrosis and will not heal spontaneously, resulting in replacement resorption $[53,66]$. Loss of the protective barrier exposes dentine, which becomes part of the remodeling process in bone, leading to ankylosis of the respective tooth [67]. After severe traumatic impact, in particular after intrusion and avulsion, replacement resorption is likely to occur, with increasing risk with unfavorable storage of the tooth, particularly dry storage for more than $60 \mathrm{~min}$ [68]. Recent studies and a systematic review reported the development of replacement resorption in more than $50 \%$ of replanted teeth after avulsion $[69,70]$. Transformation of root dentine into bone may be considered an "error" of the resorbing cells, which are unable to distinguish between these two types of tissues [15, 18]. Replacement resorption can be classified as a special type, as it progresses without additional stimulatory factors. It occurs after the acute inflammatory response has faded, cannot be associated with a bacterial stimulus and is resistant to therapeutic intervention [71, 72]. It advances to the point of complete replacement of the root by bone, leading to tooth fracture and loss of the crown [65]. The progression rate depends on the patient's age and is faster in adolescents [73] compared to older patients. As today's treatment for root resorption targets removal of the continuous stimulus, promising therapeutic concepts for replacement resorption have not been introduced, merely strategies to minimize the extent of damage [74].

External inflammatory resorption develops due to combined injuries to pulp and root cementum, particularly after luxation injuries [75, 76]. It is driven by intracanal infection after pulp necrosis in combination with damage to the cementum. Bacterial toxins, which penetrate through the dentinal tubules and beyond the damaged root surface, represent a strong stimulus to clastic cells and stimulate a rapidly progressing resorptive process [64]. The assessment of inflammatory mediators collected from gingival crevicular fluid in traumatized teeth showed a marked increase of IL- $1 \alpha, \mathrm{Il}-1 \beta$ and TNF $\alpha$ in injured versus control teeth, and IL- $1 \alpha$ was suggested as a potential biomarker for the early detection of external inflammatory root resorption after trauma [34]. This type of resorption is the result of a severe luxation and neglect of root canal treatment. After root canal disinfection, the resorptive process stops. Combinations of inflammatory and replacement resorptions are possible; in this case, root canal treatment can slow down the resorptive process considerably [1].

The etiology and pathophysiological mechanisms of cervical resorption is not yet fully understood. Triggering factors besides dental trauma may be bacteria from the gingival sulcus [17], anatomic irregularities of the enamel-cementum border or damage to the periodontal ligament by subgingival debridement [77-80], but also internal bleaching or previous orthodontic treatment $[7,15,17,81]$. Heithersay claims that initial invasion of a fibrovascular tissue with a secondary bacterial trigger and not primary microbiological involvement is responsible [82]. Data from a larger clinical study indicated that in nearly two thirds of cases, more than one potentially predisposing factor was identified, thus cervical resorption may be multifactorial [83]. Recently, diabetes has been suggested as a predisposing systemic factor for cervical resorption, as inflammation and oxidative stress, the activation of clastic cells and a promotion of angiogenesis relate to the hypoxic cellular microenvironment in these patients [84]. This finding is supported by a case report and immunohistochemical analysis of a tooth with cervical resorption after extraction, which revealed an increase of hypoxia-inducible factor $1 \alpha$-positive cells within the lesion; at the same time ectopic calcifications in the pulp confirmed the hypoxic environment [85].

Internal resorption occurs after loss of the protective predentine in combination with a continuous bacterial stimulation, where infected or necrotic pulp tissue coronally, but vital tissue apically of the resorptive process is imperative for progression [12, 18]. Bacteria may 
penetrate via dentinal tubules, carious lesions, along fracture lines or lateral canals. Since these premises are seldom met, internal resorptions are rare [15]. Whereas etiological factors are not certain, dental trauma is a likely cause [86], but periodontal disease, carious lesions, chronic pulpitis, vital pulp treatment or iatrogenic factors such as cavity preparation and orthodontic treatment have to be considered [12, 15]. Histologic analysis of teeth with internal root resorption reveal a multi-faceted character, a case report showed acute infection with multi-nucleated resorbing cells on the dentin surface at the resorption site, but normal tissue without inflammatory changes apically of the lesion in an upper canine, a second case was characterized by chronically inflamed granulation tissue with massive bacterial colonization [87].

The different type of root resorption, primary cause and additional stimuli are listed in Table 3.

\section{Protective mechanisms in permanent teeth}

The dental hard tissues cementum, dentine and enamel are not resorbed under physiological conditions; even periradicular lesions cause the resorption of bone, but rarely of dentine. Different inhibitory measures have been discussed, among them remnants of HERS, which surrounds the tooth root like a net [9]. Whereas expression of amelogenin by remnant HERS cells may have inhibitory effects on a pathological destruction of cementum [88], the role of HERS as a protective mechanism remains open.

A key factor appears to be a protective lining of the root surfaces, on one hand by precementum, on the other hand by odontoblasts and predentine [13, 89]. Cervically, the root is covered by acellular cementum, the apical third contains cellular cementum with cementocytes in lacunae and a cover layer of cementoblasts, which form a non-mineralized cementoid [9]. Osteoclasts are not capable of binding to non-mineralized surfaces [17]. Damage to this protective layer leads to exposure of dentine, where osteoclasts bind to cell-adhesive peptide sequences (RGD: arginine-glycine-aspartic acid) of matrix proteins via their integrin receptors $[90,91]$. Within the root, odontoblasts and predentine form a non-mineralized organic layer, which similarly inhibits resorption. In cervical resorption, a $200 \mu \mathrm{m}$ resorption-resistant layer made of predentine, dentine and mineralized repair tissue around the root canal prohibits penetration of the resorptive process into the pulp space. This layer can typically be observed as a characteristic radiopaque sheath around the root canal $[79,80]$. The PDL, which consists of collagenous fiber bundles bridging the gap between root cementum and alveolar bone also forms a barrier. PDL cells are involved in the formation and degradation of bone, cementum and collagen bundles [92]. They produce protease inhibitors, which prevent the adhesion of osteoclasts and the invasion of bone cells into the PDL compartment [93, 94].

Another protective barrier is the hyaline layer of Hopewell-Smith, a hypercalcified coating which aids cementum in binding to dentine. This layer prevents the penetration of bacterial products from the root canal into the PDL and vice versa [95]. Its destruction after traumatic impact in combination with a root canal infection stimulates clastic cells and leads to a rapidly progressing

Table 3 Classification of root resorption

\begin{tabular}{|c|c|c|}
\hline & Primary cause & Additional stimuli \\
\hline Transient resorption & \multicolumn{2}{|l|}{ Spatially limited damage to root cementum } \\
\hline Replacement resorption & \multicolumn{2}{|l|}{$\begin{array}{l}\text { Massive damage to root cementum (>20\% of root } \\
\text { surface) }\end{array}$} \\
\hline External inflammatory resorption & Massive damage to root cementum & Root canal infection \\
\hline \multirow[t]{9}{*}{ Cervical resorption } & \multirow[t]{9}{*}{ Damage to root cementum (?) } & Hypoxic micro-environment (?) \\
\hline & & Spatially limited damage to periodontal tissues \\
\hline & & Compromised blood supply \\
\hline & & Sulcular infection (?) \\
\hline & & $\begin{array}{l}\text { Non-overlapping enamel and root cementum } \\
\text { with exposed dentin surface (?) }\end{array}$ \\
\hline & & Bleaching \\
\hline & & Orthodontic treatment (?) \\
\hline & & Periodontal treatment (?) \\
\hline & & Endocrine/autoimmune (?) \\
\hline Internal resorption & Damage to predentine & $\begin{array}{l}\text { Pulp infection coronally of the resorptive } \\
\text { defect, apically vital tissue }\end{array}$ \\
\hline
\end{tabular}


resorption. Further intrinsic factors of cementum and dentine can inhibit the formation and activity of clastic cells. Cementoblasts and also cementocytes, in comparison to the structurally similar osteoblasts and osteocytes, produce notably higher levels of OPG, where an increased ratio of OPG to RANKL constitutes another mechanism to prevent the resorption of cementum [96].

\section{Cells involved in root resorption}

Resorption requires an elaborate interaction between resorptive osteoclasts or odontoclasts and immune cells such as monocytes, macrophages and dendritic cells [61, 97, 98].

Osteoclasts are multi-nucleated cells of $30-100 \mu \mathrm{m}$ in diameter, which are capable of bone resorption [99] and play a central role both during physiological and pathological processes [100]. Clastic cells originate from monocytic hematopoietic progenitors of bone marrow $[46,47,101,102]$. After their maturation, the process of subsequent fusion into multi-nucleated clastic cells is influenced by multiple cytokines and growth factors, particularly M-CSF and RANKL (Fig. 2) [42, 103]. M-CSF binding to its receptor induces proliferation of progenitor cells and expression of the receptor RANK [104], at the same time suppressing OPG [105]. In differentiated osteoclasts, M-CSF increases cell motility and protects them from apoptosis [106]. RANKL binding to RANK as well as M-CSF induce differentiation of osteoclasts. These are activated by RANKL and IL-1, become polarized and extend pseudopods and filopods, which enable ameboid movement [107]. They align along indentations called Howship lacunae, form a sealing zone which confines the resorptive area and disintegrate the mineralized tissue along protuberances called the "ruffled border" [108]. Whereas mononuclear osteoclasts are also capable of resorption, multi-nucleated cells are predominant as they appear to be more efficient, although cell fusion requires a high energy consumption $[109,110]$. Osteoclasts resorb up to $100 \mu \mathrm{m}^{2}$ of bone per day, which corresponds to the activity of 100 osteoblasts and reflects the high efficiency of these cells [111]. Clearance of degradation products is followed by apoptosis of osteoclasts or return to a nonresorbing state [108].

Similarly, odontoclasts are multi-nucleated cells that resorb dental hard tissues. They resemble osteoclasts and originate from the same progenitors. However, there is still no agreement as to whether odontoclasts and osteoclasts are the same $[61,112]$. Odontoclasts exhibit equal ultrastructural and histochemical properties [113-115], resorb their substrate in the same manner [116], use the same key enzymes [117, 118], form Howship lacunae, appear polarized, form a ruffled border [116] and express RANK [38]. On the other hand, odontoclasts are smaller, have fewer nuclei, form smaller sealing zones [119-121], and the calcitonin-receptor has not been identified in these cells [118]. However, odontoclasts may form two ruffled borders and resorb dentine and bone at the same time [122], and osteoclasts have been described to be capable of dentine resorption [123, 124]. Therefore, it can be deducted that osteoclasts and odontoclasts are very similar.

Macrophages, monocytes and dendritic cells derive from the same hematopoietic progenitors as osteoclasts and play important roles in the resorptive process [96, $125,126]$. Monocytes are leucocytes, which circulate in blood but can migrate into adjacent tissues and transform into macrophages. Attracted by chemotactic signals, monocytes and macrophages take up and remove foreign matter and pathogens by means of cytoplasmic, acid-containing granula, which allow them to digest debris [61, 127]. Macrophages are structurally similar to osteoclasts and remove tissue remnants generated during the resorptive process $[96,128]$. Dendritic cells have so far been looked upon as cells with solely immunologic function, but immature dendritic cells can also differentiate into clastic cells [129]. Their presence in dental pulp leads to the assumption that they are progenitors of odontoclasts [55].

\section{Pathogenesis of root resorption}

To initiate the resorptive process, osteoclasts have to migrate, fuse, adhere to the surface, polarize and form new membrane domains, then demineralize hydroxyapatite and disintegrate the organic matrix. Immunological mechanisms play an essential role for the initiation and continuation of pathological resorption [130, 131]. Obviously, osteoclasts are the link between mineralized tissues and immune system, as they share the same progenitors as classic immune cells [109]. The initial immune response is linked to the subsequent resorption, where differentiation of clastic cells is part of the repair process. Traumatic injuries cause tissue damage; necrotic cells and local release of cytokines and chemokines attract T-cells, which in turn recruit and activate macrophages and granulocytes. Disintegration of tissue barriers allows microorganisms to enter, and bacterial toxins fortify this process. Macrophages ingest tissue debris and microbes, and produce cytokines such as IL- $1 \beta$ and TNF $\alpha$, but also calcitriol, PGE2 and dexamethasone, which stimulate the expression of RANKL in PDL fibroblasts and T-cells $[132,133]$. Several studies describe the regulation of bone resorption, but there is evidence that the same proinflammatory cytokines, namely IL-1 and TNF $\alpha$ are involved in root resorption $[134,135]$.

The process of cell adhesion appears to be indispensable for osteoclast maturation [136]. Binding to dentin 
sialoprotein and the RGD-motif [137] via the integrin receptor causes a reorganization of the cytoskeleton and the stimulation of resorption [138]. Integrins and cadherins furthermore enable cell mobility, signal transduction, matrix recognition and induction of resorption $[108,139]$. Interestingly, clastic cells bind to dentine better than to bone, the sealing zone shows a longer halflife, and resorption lacunae develop faster [140, 141]. This characteristic structure drives the actual resorption, where hydroxyl- and chloride ions are pumped into the Howship-lacuna to form hydrochloric acid, the $\mathrm{pH}$ drops to 4.5 and hydroxyapatite crystals disintegrate $[142,143]$. Subsequently, enzymes such as TRAP or cathepsin $\mathrm{K}$, procollagenases and matrix metalloproteinases are secreted to degrade the organic matrix $[46,139]$. In combination, acid and proteases successively degrade the mineralized tissue [144], and calcium and phosphate ions as well as collagen fragments are removed by the osteoclast via transcytosis. Whereas pathophysiological processes during bone resorption have been described, and attention has been paid to resorption after orthodontic movement or in deciduous teeth, studies on traumainduced root resorption are rare. As evidence is accumulating that cells and mediators are identical, it appears likely that insights from research on bone is transferrable to the resorption of dentine and cementum during root resorption. RANKL/RANK/OPG control bone resorption as well as root resorption, and the underlying cellular mechanisms appear to be alike $[105,118,132$, 145-147]. RANKL is expressed by osteoblasts, but also odontoblasts, pulp- and PDL-fibroblasts, cementoblasts and activated T-cells [37], OPG by odontoblasts, ameloblasts, pulp- and PDL-fibroblasts [148, 149]. RANKL can be found in deciduous teeth undergoing resorption [118, $150,151]$, on the contrary, PDL cells in non-resorbing deciduous teeth and in permanent teeth express OPG but not RANKL. Similarly, RANKL is involved in root resorption due to mechanical stress during orthodontic movement, where PDL cells increase RANKL, but decrease OPG expression [133, 145, 146, 152]. Evidence from the literature is sparse, but it seems that the underlying mechanisms of RANKL expression and OPG suppression are similar after dental trauma. Interestingly, topical treatment of the root surface with denosumab, a human monoclonal antibody that mimics the effects of osteoprotegerin in bone metabolism, inhibited the expression of RANKL and reduced root resorption after 2 months considerably in a rat model after extraction and replantation after an extraoral dry time of $60 \mathrm{~min}$ [153]. Topical application of alendronate, an osteoclast inhibitor used to treat osteoporosis, showed similar effects [154]. Along these lines, the application of the antioxidant $\mathrm{N}$-acetylcyteine as intracanal medicament in a similar animal model led to reduced levels of RANK, the number of clastic cells and the extent of resorption [155]. Such findings highlight the potential of pharmacological approaches to decrease the extent of resorptive processes in situations which are currently not susceptible to therapeutic intervention. Bacterial infection often accompanies the progression of root resorption. PDL cells stimulated with Prevotella intermedia or Porphyromonas gingivalis increase RANKL-production [156]. LTA, the biologically active surface component of grampositive bacteria may cause resorption via the same mechanism [157].

Whereas in most resorptive processes, resorption appears to be dominant, cervical resorption shows different phases [158]. During the initiation stage, local destruction of the periodontium induces an immune response and formation of granulation tissue in contact with dentine, which can lead to clastic activity after activation of the RANK/RANKL system. The second phase of resorption is characterized by progression. A third, reparative stage can be observed later on, where formation of new bone-like tissue takes place. In cervical resorption, resorptive processes can be observed simultaneously with repair in different areas of the affected tooth [158].

\section{Stimulators and inhibitors of resorption}

Stimulators of bone resorption include systemic factors, such as PTH and calcitriol. PTH stimulates RANKL expression in osteoblasts and directly influences osteoclast fusion. Similarly, PDL cells react to PTH, which suggests that hormonal or mechanical stimulation may change the ratio of OPG and RANKL in these cells [132, $151,159]$ and thus regulate the activity of periodontal tissues. Furthermore, PTH positively influences tooth eruption and orthodontic movement [160-162]. Calcitriol increases the resorptive activity of mature osteoclasts without increasing their quantity [61].

Besides systemic factors, locally expressed factors stimulate resorptive processes. Macrophages and leucocytes produce these cytokines during inflammation in response to bacteria, tissue debris and other cytokines, where most of these factors affect the RANKL/RANK/ OPG system. IL-1 is involved in the resorption of periapical and periodontal tissues [163, 164], as it activates osteoclasts and stimulates the production of inflammatory mediators such as PGE2. IL-6 increases this effect by inducing RANKL expression in stromal cells and enhancing osteoclast differentiation [165]. PGE2 itself upregulates the activity of cementoclasts by controlling RANKL/ OPG expression in cementoblasts [166], which illustrates the close interconnection of resorptive process and inflammatory response. Inflammation, vasoconstriction, 
enhanced clotting and transmission of pain are concomitant events of this process.

Bacteria themselves are stimulators of resorption, as they produce acids and proteases that degrade matrix components and tissues. During root resorption, LPS from cell walls of gramnegative bacteria stimulate osteoclast activity directly, but also indirectly by inducing the production of osteolytic factors by osteoblasts and macrophages. Enzymes and collagenases as well as IL-1, IL-6, M-CSF und PGE2 increase osteoclast activity [165]. It has been shown that bacteria such as Treponema denticola, Porphyromonas gingivalis and Treponema socranskii induce osteoclast formation via increased RANKL and PGE2 and decreased OPG [167]. Similar mechanisms have been observed for surface components of grampositive bacteria.

Inhibitory factors of clastic cells and thus resorptive processes include the hormone calcitonin, which reduces the motility of clastic cells and makes them withdraw from the resorption front. Calcitonin is effective at minute concentrations, its receptor CTR is expressed by osteoclasts $[168,169]$. Inhibitory effects of calcitonin have also been demonstrated for odontoclasts, although the presence of CTR on these cells has not been proven yet $[118,170]$. Inhibitory effects have also been shown for estrogen, furthermore for interferon and corticosteroids. Besides these systemic factors, again local cytokines inhibit clastic cells, among them IL-4, IL-8, IL-10 and IL-18 [171, 172].

FGF-2 may take on different roles, it appears to have stimulatory effects on osteoclast differentiation and increases PGE2 production [173], on the other hand it may antagonize M-CSF and directly inhibit osteoclast precursors [174].

\section{Discussion}

In this scoping review, the existing knowledge of pathophysiological mechanisms of root resorption after dentoalveolar trauma was systematically searched, collected, processed, integrated and summarized in a condensed yet comprehensive form.

Standards exist for the methodological approach for systematic reviews and meta-analyses. For new forms of preparation of evidence such as scoping reviews or evidence maps, full consensus has yet to be achieved. The existing literature exhibits discrepancies in recommended methods, and consistent definitions are lacking. Recent methodological papers present specifications regarding the approach and nomenclature and confine scoping reviews from the classical systematic reviews [68, 175-177]. Thus, the PRISMA-statement for systematic reviews and meta-analyses was adapted to the PRISMAScR checklist, which provides guidance [24]. The scoping review differs from a systematic review by asking a broad question instead of posing a precise problem and narrow topic. For systematic reviews, the literature search follows strictly defined inclusion- and exclusion criteria, oftentimes the choice of publications is limited to a specific study design [175]. Systematic reviews are based on the PICO scheme explicitly following the parameters patient/population, intervention, control intervention and outcome. The design may prohibit a comprehensive and yet up-to-date overview of the topic of choice, including all facets and sub-categories. Therefore, there is an increasing demand for different forms, which systematically summarize recent research findings and present evidence as well as evidence gaps [175]. Increasing numbers of scoping reviews and evidence maps, which reflect these considerations, are published to date. Whereas scoping reviews and evidence maps assess where consolidated knowledge ends and additional research is needed, systematic reviews clarify whether existing knowledge is reliable. Differences between the two forms of review are summarized in Table 4 [175]. With regard to the topic and aim of this work, a scoping review appears to be the ideal format [178]. Although the search for our study might not be as sensitive as for a systematic review, the literature identified to answer the question for this review was exhaustive. Since information on the regulation of trauma-associated root resorption is scarce, a strength of this review may be the synthesis of research findings from different fields, as knowledge, e.g. from mineralized tissue research on pathological resorption as well as from orthodontics is transferrable and applicable. Thus, a more detailed picture of root resorption can be presented.

A disadvantage of the chosen research concept is the large number of records from the database searches which needed intellectual selection imposing a substantial amount of effort. Inclusion and exclusion criteria for the present study were not as strictly defined as it is typical for systematic reviews, therefore the material was selected by thematic content rather than set characteristics of study design and factual accomplishment. The selection process required an individual, topic-based decision of whether to include or exclude each of the articles found after the primary search. This individual interpretation and rating of relevance influences the selection and eventually the body of literature that the analysis and summary of factors was based on, which might have resulted in bias and a contortion of the presented results. However, sensitive searching of multiple databases in combination with the manual searches and the resurvey of the relevant literature based on the demarcation set for this study counteracts this possible source of bias.

The thorough search and intense review of the existing literature revealed a body of knowledge, but also 
Table 4 Comparison of systematic and scoping reviews [164]

\begin{tabular}{|c|c|c|}
\hline & Systematic review & Scoping review \\
\hline \multirow[t]{3}{*}{ Aims } & $\begin{array}{l}\text { Systematic assessment and evaluation of } \\
\text { evidence }\end{array}$ & Systematic mapping of evidence and identification of gaps \\
\hline & & Evaluation whether systematic review is necessary \\
\hline & & Identification of research needs \\
\hline \multirow[t]{3}{*}{ Question } & Precise, narrow & Broad, beyond interventions, disease patterns or diagnostic measures \\
\hline & Similar to primary studies & \\
\hline & & $\begin{array}{l}\text { No limitations in regard to the question, control interventions or } \\
\text { command variable }\end{array}$ \\
\hline Study Design & Determined by question & Any \\
\hline Quality Assessment & Yes & Not intended \\
\hline \multirow[t]{2}{*}{ Presentation of Results } & Descriptive, often quantitative & Descriptive \\
\hline & & Unweighted evidence \\
\hline
\end{tabular}

redundant information, controversial findings, knowledge gaps, lack of evidence and the need for further research. Repeated speculation without concrete sources can be found, which suggests that many aspects of this topic have not been explored and understood. This may be due to the complexity of regulatory processes, minor awareness of the problem, and a lack of suitable research models. Subsequently, late detection of root resorption is still common, which can result even in the loss of teeth, often in a critical zone of growth and esthetics, with rather unfavorable longterm consequences for patients which could have been prevented otherwise. For clinical practice, the understanding of etiological factors and the distinction of whether or not they can be influenced implies therapeutic approaches. Thus, more detailed insight into the pathomechanisms of cervical resorption might lead to more effective prevention and treatment. Replacement resorption poses another great challenge: whereas antiresorptive application of tetracycline [179] and/or corticosteroids [179] may inhibit clastic cells and thus defer and limit the extent of resorption, the process is unstoppable once it has commenced. Future research towards local pharmacologic approaches to prevent remodeling of dentine into bone harbors potential for major benefits for trauma patients. The establishment of animal models to study dentine resorption, e.g. by ectopic implantation of dentine chips after different pre-treatment may help to test the influence of different parameters on the resorptive process and develop strategies to control or avert resorption. Last but not least, more systematic education and thorough training of dental students and young professionals will be an important step towards prevention, early detection and optimized therapy of root resorption in patients who have suffered from dental trauma.

\section{Conclusion}

The comprehensive overview of the pathophysiological mechanisms of trauma-induced root resorption may contribute to an increase awareness, draw attention to this complex topic and generate future research activities. This may impact patient care and improve the long-term prognosis of teeth that are at the risk of root resorption.

\section{Abbreviations}

PRISMA(-SCR): Preferred reporting items for systematic reviews and metaanalysis (extension for scoping reviews); RANKL: Receptor activator of NF-KB ligand; RANK: Receptor activator of NF-kB; OPG: Osteoprotegerin; PTH: Parathyroid hormone; HERS: Hertwig's epithelial root sheet; PDL: Periodontal ligament; M-CSF: Macrophage colony-stimulating factor; PGE2: Prostaglandin E2; LTA: Lipoteichoic acid; LPS: Lipopolysaccharide; FGF-2: Fibroblast-growthfactor 2

\section{Supplementary Information}

The online version contains supplementary material available at https://doi. org/10.1186/s12903-021-01510-6.

Additional file 1: Preferred reporting items for systematic reviews and meta-analyses extension for scoping reviews (PRISMA-SCR) checklist.

Additional file 2: Electronic Search Strategies as exported from the search interfaces with only some formatting applied.

\section{Acknowledgements}

Not Applicable.

\section{Authors' contributions}

KMG, EMG, MW, WB and HK contributed to the conception and design of the work. EMG, KMG and HK performed the data inclusion and analysis. MW and WB contributed to interpretation of data. KMG, EMG, MW and HK participated in manuscript writing and revision. All authors read and approved the final manuscript.

Funding

Open Access funding enabled and organized by Projekt DEAL. 


\section{Availability of data and materials}

The dataset used and/or analyzed during the current study available from the corresponding author on reasonable request.

\section{Declarations}

Ethics approval and consent to participate

Not applicable.

\section{Consent for publication}

Not applicable.

\section{Competing interests}

The authors declare that they have no competing interests.

\section{Author details}

${ }^{1}$ Department of Conservative Dentistry and Periodontology, University Hospital Regensburg, Franz-Josef-Strauß Allee 11, 93053 Regensburg, Germany.

2 University Library, University of Regensburg, Regensburg, Germany.

Received: 29 September 2020 Accepted: 11 March 2021

Published online: 26 March 2021

\section{References}

1. Andreasen JO, Andreasen FM, Andersson L. Textbook and color atlas of traumatic injuries to the teeth. New York: Wiley-Blackwell; 2018.

2. Cavalleri G, Zerman N. Traumatic crown fractures in permanent incisors with immature roots: a follow-up study. Endod Dent Traumatol. 1995;11:294-6.

3. Oikarinen K, Gundlach KK, Pfeifer G. Late complications of luxation injuries to teeth. Endod Dent Traumatol. 1987;3:296-303.

4. von Arx T, Wenger P, Hardt N. Spätfolgen nach Traumata bleibender Zähne bei Kindern. Acta Med Dent Helv. 1998;3:196-202.

5. Mediero A, Wilder T, Shah L, Cronstein BN. Adenosine A2A receptor (A2AR) stimulation modulates expression of semaphorins $4 \mathrm{D}$ and $3 \mathrm{~A}$, regulators of bone homeostasis. FASEB J. 2018;32:1-29.

6. Dunsche A, Ewers R, Filippi A, Hoffmeister B, Wangerin K. Oral and implant surgery. Batavia: Quintessence Publishing; 2009.

7. Andreasen JO. External root resorption: its implication in dental traumatology, paedodontics, periodontics, orthodontics and endodontics. Int Endod J. 1985;18:109-18.

8. Cochran DL. Inflammation and bone loss in periodontal disease. J Periodontol. 2008;79:1569-76.

9. Hammarstrom L, Lindskog S. General morphological aspects of resorption of teeth and alveolar bone. Int Endod J. 1985;18:93-108.

10. Lindskog S, Blomlöf L, Hammarstrom L. Cellular colonization of denuded root surfaces in vivo: cell morphology in dentin resorption and cementum repair. J Clin Periodontol. 1987;14:390-5.

11. Hadjidakis DJ, Androulakis II. Bone remodeling. Ann NY Acad Sci. 2006;1092:385-96.

12. Wedenberg C, Lindskog S. Experimental internal resorption in monkey teeth. Endod Dent Traumatol. 1985;1:221-7.

13. Wedenberg C, Lindskog S. Evidence for a resorption inhibitor in dentin. Scand J Dent Res. 1987;95:205-11.

14. Bratteberg M, Thelen DS, Klock KS, Bårdsen A. Traumatic dental injuries and pulp sequelae in an adolescent population. Dent Traumatol. 2020. https://doi.org/10.1111/edt.12635.

15. Tronstad L. Root resorption-etiology, terminology and clinical manifestations. Endod Dent Traumatol. 1988:4:241-52

16. Trope M. Root resorption of dental and traumatic origin: classification based on etiology. Pract Periodontics Aesthet Dent. 1998;10:515-22.

17. Trope M. Root resorption due to dental trauma. Endod Top. 2002;1:79-100.

18. Fuss Z, Tsesis I, Lin S. Root resorption-diagnosis, classification and treatment choices based on stimulation factors. Dent Traumatol. 2003:19:175-82

19. Patel S, Pitt FT. Is the resorption external or internal? Dent Update. 2017:34:218-29.
20. AAE. Glossary of Endodontic Terms. 10th edition, 2019.

21. Peterson J, Pearce PF, Ferguson LA, Langford CA. Understanding scoping reviews: definition, purpose, and process. J Am Assoc Nurse Pract. 2017;29:12-6.

22. Davies S. The importance of PROSPERO to the National Institute for Health Research. Syst Rev. 2012;1:5-2.

23. Moher D, Liberati A, Tetzlaff J, Altman DG, Grp P. Preferred reporting items for systematic reviews and meta-analyses: the PRISMA statement. PLoS Med. 2009:6:e1000097.

24. Tricco AC, Lillie E, Zarin W, O'Brien KK, Colquhoun H, Levac D, et al. prisma extension for scoping reviews (PRISMA-SCR): checklist and explanation. Ann Intern Med. 2018;169:467-73.

25. McGowan J, Sampson M, Salzwedel DM, Cogo E, Foerster V, Lefebvre C. PRESS peer review of electronic search strategies: 2015 guideline statement. J Clin Epidemiol. 2016;75:40-6.

26. Rucci N. Molecular biology of bone remodelling. Clin Cases Miner Bone Metab. 2008;5:49-56.

27. Cohen MM. The new bone biology: pathologic, molecular, and clinical correlates. Am J Med Genet A. 2006;140:2646-706.

28. Teitelbaum SL. Osteoclasts: what do they do and how do they do it? Am J Pathol. 2007;170:427-35.

29. Karsdal MA, Neutzsky-Wulff AV, Dziegiel MH, Christiansen C, Henriksen K. Osteoclasts secrete non-bone derived signals that induce bone formation. Biochem Biophys Res Commun. 2008;366:483-8.

30. Lerner UH. New molecules in the tumor necrosis factor ligand and receptor superfamilies with importance for physiological and pathological bone resorption. Crit Rev Oral Biol Med. 2004;15:64-81.

31. Boyce BF, Xing L. Functions of RANKL/RANK/OPG in bone modeling and remodeling. Arch Biochem Biophys. 2008;473:139-46.

32. Silva I, Branco JC. Rank/Rankl/opg: literature review. Acta Reumatol Port. 2011;36:209-18.

33. Boyce BF, Xing L. Biology of RANK, RANKL, and osteoprotegerin. Arthritis Res Ther. 2007;9(Suppl 1):1-7.

34. Gregorczyk-Maga I, Kaszuba M, Olszewska M, Lichołai S, Iwaniec T, Kościelniak D, et al. Biomarkers of inflammatory external root resorption as a result of traumatic dental injury to permanent teeth in children. Arch Oral Biol. 2019;99:82-91.

35. Yasuda H, Shima N, Nakagawa N, Yamaguchi K, Kinosaki M, Mochizuki $\mathrm{S}$, et al. Osteoclast differentiation factor is a ligand for osteoprotegerin/ osteoclastogenesis-inhibitory factor and is identical to TRANCE/RANKL. Proc Natl Acad Sci USA. 1998;95:3597-602.

36. Khosla S. Minireview: the OPG/RANKL/RANK system. Endocrinology. 2001;142:5050-5.

37. Schoppet M, Preissner KT, Hofbauer LC. RANK ligand and osteoprotegerin: paracrine regulators of bone metabolism and vascular function. Arterioscler Thromb Vasc Biol. 2002:22:549-53.

38. Harokopakis-Hajishengallis E. Physiologic root resorption in primary teeth: molecular and histological events. J Oral Sci. 2007;49:1-12.

39. Lossdörfer S, Götz W, Jäger A. Immunohistochemical localization of receptor activator of nuclear factor kappaB (RANK) and its ligand (RANKL) in human deciduous teeth. Calcif Tissue Int. 2002:71:45-52.

40. Anderson DM, Maraskovsky E, Billingsley WL, Dougall WC, Tometsko ME, Roux ER, et al. A homologue of the TNF receptor and its ligand enhance T-cell growth and dendritic-cell function. Nature. 1997;390:175-9.

41. Darnay BG, Haridas V, Ni J, Moore PA, Aggarwal BB. Characterization of the intracellular domain of receptor activator of NF-kappaB (RANK). Interaction with tumor necrosis factor receptor-associated factors and activation of NF-kappab and c-Jun N-terminal kinase. J Biol Chem. 1998;273:20551-5.

42. Suda T, Takahashi N, Udagawa N, Jimi E, Gillespie MT, Martin TJ. Modulation of osteoclast differentiation and function by the new members of the tumor necrosis factor receptor and ligand families. Endocr Rev. 1999;20:345-57.

43. Tyrovola JB, Spyropoulos MN, Makou M, Perrea D. Root resorption and the OPG/RANKL/RANK system: a mini review. J Oral Sci. 2008;50:367-76.

44. Kohli SS, Kohli VS. Role of RANKL-RANK/osteoprotegerin molecular complex in bone remodeling and its immunopathologic implications. Indian J Endocrinol Metab. 2011;15:175-81.

45. Takeda S. Central control of bone remodelling. J Neuroendocrinol. 2008;20:802-7. 
46. Roodman GD. Cell biology of the osteoclast. Exp Hematol. 1999;27:1229-41.

47. Kurihara N, Suda T, Miura Y, Nakauchi H, Kodama H, Hiura K, et al. Generation of osteoclasts from isolated hematopoietic progenitor cells. Blood. 1989;74:1295-302.

48. Cohen S. Role of RANK ligand in normal and pathologic bone remodeling and the therapeutic potential of novel inhibitory molecules in musculoskeletal diseases. Arthritis Rheum. 2006;55:15-8.

49. Mizuno A, Kanno T, Hoshi M, Shibata O, Yano K, Fujise N, et al. Transgenic mice overexpressing soluble osteoclast differentiation factor (sODF) exhibit severe osteoporosis. J Bone Miner Metab. 2002;20:337-44.

50. Sojod B, Chateau D, Mueller CG, Babajko S, Berdal A, Lézot F, et al. RANK/RANKL/OPG signalization implication in periodontitis: new evidence from a rank transgenic mouse model. Front Physiol. 2017;8:338.

51. Gravallese EM, Harada Y, Wang JT, Gorn AH, Thornhill TS, Goldring SR. Identification of cell types responsible for bone resorption in rheumatoid arthritis and juvenile rheumatoid arthritis. Am J Pathol. 1998;152:943-51.

52. Walsh NC, Crotti TN, Goldring SR, Gravallese EM. Rheumatic diseases: the effects of inflammation on bone. Immunol Rev. 2005:208:228-51.

53. Andreasen $\mathrm{JO}$, Kristerson $\mathrm{L}$. The effect of limited drying or removal of the periodontal ligament. Acta Odontol Scand. 1981;39:1-13.

54. de Aguiar Santos BO, de Mendonça DS, de Sousa DL, Moreira Neto JJS, de Araújo RBR. Root resorption after dental traumas: classification and clinical, radiographic and histologic aspects. RSBO. 2011;8:439-45.

55. Patel S, Ricucci D, Durak C, Tay F. Internal root resorption: a review. J Endod. 2010;36:1107-21.

56. Friedman S, Rotstein I, Libfeld H, Stabholz A, Heling I. Incidence of external root resorption and esthetic results in 58 bleached pulpless teeth. Endod Dent Traumatol. 1988:4:23-6.

57. Levander E, Malmgren O. Evaluation of the risk of root resorption during orthodontic treatment: a study of upper incisors. Eur J Orthod. 1988;10:30-8

58. Bakland LK. Root resorption. Dent Clin N Am. 1992;36:491-507.

59. Sringkarnboriboon S, Matsumoto Y, Soma K. Root resorption related to hypofunctional periodontium in experimental tooth movement. J Dent Res. 2003;82:486-90.

60. Bansal P, Nikhil V, Kapur S. Multiple idiopathic external apical root resorption: a rare case report. J Conserv Dent. 2015;18:70-2.

61. Ne RF, Witherspoon DE, Gutmann JL. Tooth resorption. Quintessence Int. 1999;30:9-25.

62. Andreasen JO, Andreasen FM. Root resorption following traumatic dental injuries. Proc Finn Dent Soc. 1992;88(Suppl 1):95-114.

63. Shaw DR, Griffin FM. Phagocytosis requires repeated triggering of macrophage phagocytic receptors during particle ingestion. Nature. 1981;289:409-11.

64. Andreasen JO. Relationship between surface and inflammatory resorption and changes in the pulp after replantation of permanent incisors in monkeys. J Endod. 1981;7:294-301.

65. Andreasen JO, Hiørting-Hansen E. Replantation of Teeth. II. Histological study of 22 replanted anterior teeth in humans. Acta Odontol Scand. 1966;24:287-306.

66. Andreasen JO. Periodontal healing after replantation of traumatically avulsed human teeth: assessment by mobility testing and radiography. Acta Odontol Scand. 2009:33:325-33.

67. Andreasen JO. Periodontal healing after replantation and autotransplantation of incisors in monkeys. Int J Oral Surg. 1981;10:54-61.

68. Sutton A, Clowes M, Preston L, Booth A. Meeting the review family: exploring review types and associated information retrieval requirements. Health Info Libr J. 2019;36:202-22.

69. Müller DD, Bissinger R, Reymus M, Bücher K, Hickel R, Kühnisch J. Survival and complication analyses of avulsed and replanted permanent teeth. Sci Rep. 2020;10:2841-9.

70. Souza BDM, Dutra KL, Kuntze MM, Bortoluzzi EA, Flores-Mir C, ReyesCarmona J, et al. Incidence of root resorption after the replantation of avulsed teeth: a meta-analysis. J Endod. 2018;44:1216-27.
71. Andreasen JO, Borum MK, Jacobsen HL, Andreasen FM. Replantation of 400 avulsed permanent incisors. 4. Factors related to periodontal ligament healing. Dent Traumatol. 1995;11:76-89.

72. Tsilingaridis G, Malmgren B, Skutberg C, Malmgren O. The effect of topical treatment with doxycycline compared to saline on 66 avulsed permanent teeth-a retrospective case-control study. Dent Traumatol. 2015;31:171-6.

73. Andersson L, Bodin I, Sörensen S. Progression of root resorption following replantation of human teeth after extended extraoral storage. Endod Dent Traumatol. 1989;5:38-47.

74. Blomlöf L, Lindskog S, Andersson L, Hedström KG, Hammarstrom L. Storage of experimentally avulsed teeth in milk prior to replantation. J Dent Res. 1983;62:912-6.

75. Andreasen FM, Pedersen BV. Prognosis of luxated permanent teeth-the development of pulp necrosis. Endod Dent Traumatol. 1985;1:207-20.

76. Andreasen JO, Borum MK, Jacobsen HL, Andreasen FM. Replantation of 400 avulsed permanent incisors. 2. Factors related to pulpal healing. Dent Traumatol. 1995:11:59-68.

77. Heithersay GS. External root resorption. Ann R Australas Coll Dent Surg. 1994;12:46-59.

78. Heithersay GS. Invasive cervical resorption following trauma. Aust Endod J. 1999:25:79-85.

79. Mavridou AM, Pyka G, Kerckhofs G, Wevers M, Bergmans L, Gunst V, et al. A novel multimodular methodology to investigate external cervical tooth resorption. Int Endod J. 2016;49:287-300.

80. Mavridou AM, Hauben E, Wevers M, Schepers E, Bergmans L, Lambrechts P. Understanding external cervical resorption in vital teeth. J Endod. 2016:42:1737-51.

81. Kandalgaonkar SD, Gharat LA, Tupsakhare SD, Gabhane MH. Invasive cervical resorption: a review. J Int Oral Health. 2013;5:124-30.

82. Heithersay GS. Invasive cervical resorption: an analysis of potential predisposing factors. Quintessence Int. 1999;30:83-95.

83. Mavridou AM, Bergmans L, Barendregt D, Lambrechts P. Descriptive analysis of factors associated with external cervical resorption. J Endod. 2017:43:1602-10.

84. Irinakis E, Aleksejuniene J, Shen Y, Haapasalo M. External cervical resorption: a retrospective case-control study. J Endod. 2020;46:1420-7.

85. Mavridou AM, Hilkens P, Lambrichts I, Hauben E, Wevers M, Bergmans L, et al. Is Hypoxia related to external cervical resorption? A case report. J Endod. 2019;45:459-70.

86. Calişkan MK, Türkün M. Prognosis of permanent teeth with internal resorption: a clinical review. Endod Dent Traumatol. 1997:13:75-81.

87. Koehne T, Zustin J, Amling M, Friedrich RE. Radiological and histopathological features of internal tooth resorption. In Vivo. 2020;34:1875-82.

88. Hatakeyama J, Sreenath T, Hatakeyama Y, Thyagarajan T, Shum L, Gibson CW, et al. The receptor activator of nuclear factor-kappa B ligand-mediated osteoclastogenic pathway is elevated in amelogenin-null mice. J Biol Chem. 2003;278:35743-8.

89. Wedenberg C, Yumita S. Evidence for an inhibitor of osteoclast attachment in dentinal matrix. Endod Dent Traumatol. 1990;6:255-9.

90. Nakamura I, Takahashi N, Sasaki T, Jimi E, Kurokawa T, Suda T. Chemical and physical properties of the extracellular matrix are required for the actin ring formation in osteoclasts. J Bone Miner Res. 1996:11:1873-9.

91. Schaffner P, Dard MM. Structure and function of RGD peptides involved in bone biology. Cell Mol Life Sci. 2003;60:119-32.

92. Melcher AH. On the repair potential of periodontal tissues. J Periodontol. 1976;47:256-60.

93. Lindskog S, Hammarstrom L. Evidence in favor of an anti-invasion factor in cementum or periodontal membrane of human teeth. Scand J Dent Res. 1980;88:161-3.

94. Melcher AH, Turnbull RS. Inhibition of osteogenesis by periodontal ligament. J Periodont Res. 1972;10:16-7.

95. Rathe F, Nolken R, Deimling D, Ratka-Kruger P. Externe Wurzelresorption. Schweiz Monatsschr Zahnmed. 2006;1 16:245-53.

96. Iglesias-Linares A, Hartsfield JK. Cellular and molecular pathways leading to external root resorption. J Dent Res. 2017:96:145-52.

97. Teitelbaum SL, Stewart CC, Kahn AJ. Rodent peritoneal macrophages as bone resorbing cells. Calcif Tissue Int. 1979;27:255-61.

98. Mundy CR, Altman AJ, Gondek MD, Bandelin JG. Direct resorption of bone by human monocytes. Science. 1977;196:1109-11. 
99. Baron R, Neff L, Van Tran P, Nefussi JR, Vignery A. Kinetic and cytochemical identification of osteoclast precursors and their differentiation into multinucleated osteoclasts. Am J Pathol. 1986;122:363-78.

100. Wannfors K, Hammarstrom L. Infectious foci in chronic osteomyelitis of the jaws. Int J Oral Surg. 1985;14:493-503.

101. Kember NF. Cell division in endochondral ossification. A study of cell proliferation in rat bones by the method of tritiated thymidine autoradiography. J Bone Joint Surg Br. 1960;42B:824-39.

102. Ash P, Loutit JF, Townsend KM. Osteoclasts derived from haematopoietic stem cells. Nature. 1980;283:669-70.

103. Teitelbaum SL, Ross FP. Genetic regulation of osteoclast development and function. Nat Rev Genet. 2003;4:638-49.

104. Arai F, Miyamoto T, Ohneda O, Inada T, Sudo T, Brasel K, et al. Commitment and differentiation of osteoclast precursor cells by the sequential expression of c-Fms and receptor activator of nuclear factor kappaB (RANK) receptors. J Exp Med. 1999;190:1741-54.

105. Wise GE, Yao S, Zhang Q, Ren Y. Inhibition of osteoclastogenesis by the secretion of osteoprotegerin in vitro by rat dental follicle cells and its implications for tooth eruption. Arch Oral Biol. 2002:47:247-54.

106. Fuller K, Owens JM, Jagger CJ, Wilson A, Moss R, Chambers TJ. Macrophage colony-stimulating factor stimulates survival and chemotactic behavior in isolated osteoclasts. J Exp Med. 1993;178:1733-44.

107. Chambers TJ, Revell PA, Fuller K, Athanasou NA. Resorption of bone by isolated rabbit osteoclasts. J Cell Sci. 1984;66:383-99.

108. Väänänen HK, Zhao H, Mulari M, Halleen JM. The cell biology of osteoclast function. J Cell Sci. 2000:113:377-81.

109. Bar-Shavit Z. The osteoclast: a multinucleated, hematopoietic-origin, bone-resorbing osteoimmune cell. J Cell Biochem. 2007:102:1130-9.

110. Domon T, Osanai M, Yasuda M, Seki E, Takahashi S, Yamamoto T, et al. Mononuclear odontoclast participation in tooth resorption: the distribution of nuclei in human odontoclasts. Anat Rec. 1997;249:449-57.

111. Albrektsson T, Jacobsson $M$, Turesson I. Bone remodelling at implant sites after irradiation injury. Methodological approaches to study the effects of Co60 administered in a single dose of 15 Gy. Swed Dent J. 1985;28:193-203.

112. GötzW, Quondamatteo F, Ragotzki S, Affeldt J, Jäger A. Localization of cathepsin D in human odontoclasts. A light and electron microscopical immunocytochemical study. Connect Tissue Res. 2000;41:185-94.

113. Sasaki T, Motegi N, Suzuki H, Watanabe C, Tadokoro K, Yanagisawa T, et al. Dentin resorption mediated by odontoclasts in physiological root resorption of human deciduous teeth. Am J Anat. 1988;183:303-15.

114. Sahara N, Toyoki A, Ashizawa Y, Deguchi T, Suzuki K. Cytodifferentiation of the odontoclast prior to the shedding of human deciduous teeth: an ultrastructural and cytochemical study. Anat Rec. 1996;244:33-49.

115. Sahara N, Ashizawa Y, Nakamura K, Deguchi T, Suzuki K. Ultrastructural features of odontoclasts that resorb enamel in human deciduous teeth prior to shedding. Anat Rec. 1998;252:215-28.

116. Pierce AM. Experimental basis for the management of dental resorption. Endod Dent Traumatol. 1989:5:255-65.

117. Nilsen R, Magnusson BC. Enzyme histochemistry of induced heterotropic bone formation in guinea-pigs. Arch Oral Biol. 1979:24:833-41.

118. Oshiro T, Shibasaki Y, Martin TJ, Sasaki T. Immunolocalization of vacuolartype H+-ATPase, cathepsin K, matrix metalloproteinase-9, and receptor activator of NFkappaB ligand in odontoclasts during physiological root resorption of human deciduous teeth. Anat Rec. 2001;264:305-11.

119. Furseth $R$. The resorption processes of human deciduous teeth studied by light microscopy, microradiography and electron microscopy. Arch Oral Biol. 1968;13:417-31.

120. Birkedal-Hansen $\mathrm{H}$. Osteoclastic resorption of $3 \mathrm{H}$-proline labelled bone, dentine and cementum in the rat. Calcif Tissue Res. 1974;15:77-80.

121. Lasfargues JJ, Saffar JL. Inhibition of prostanoid synthesis depresses alveolar bone resorption but enhances root resorption in the rat. Anat Rec. 1993;237:458-65.

122. Wesselink PR, Beertsen W, Everts V. Resorption of the mouse incisor after the application of cold to the periodontal attachment apparatus. Calcif Tissue Int. 1986;39:11-21.

123. Boyde A, Ali NN, Jones SJ. Resorption of dentine by isolated osteoclasts in vitro. Br Dent J. 1984;156:216-20.
124. Jones SJ, Boyde A, Ali NN. The resorption of biological and non-biological substrates by cultured avian and mammalian osteoclasts. Anat Embryol. 1984;170:247-56.

125. Babaji P, Devanna R, Jagtap K, Chaurasia VR, Jerry JJ, Choudhury BK, et al. The cell biology and role of resorptive cells in diseases: A review. Ann Afr Med. 2017;16:39-45.

126. Akamine A, Hashiguchi I, Toriya Y, Maeda K. Immunohistochemical examination on the localization of macrophages and plasma cells in induced rat periapical lesions. Endod Dent Traumatol. 1994:10:121-8.

127. Kamat $M$, Puranik $R$, Vanaki $S$, Kamat $S$. An insight into the regulatory mechanisms of cells involved in resorption of dental hard tissues. J Oral Maxillofac Pathol. 2013;17:228-33.

128. Rifkin BR, Baker RL, Somerman MJ, Pointon SE, Coleman SJ, Au WY. Osteoid resorption by mononuclear cells in vitro. Cell Tissue Res. 1980;210:493-500.

129. Speziani C, Rivollier A, Gallois A, Coury F, Mazzorana M, Azocar O, et al. Murine dendritic cell transdifferentiation into osteoclasts is differentially regulated by innate and adaptive cytokines. Eur J Immunol. 2007;37:747-57.

130. Horowitz M, Vignery A, Gershon RK, Baron R. Thymus-derived lymphocytes and their interactions with macrophages are required for the production of osteoclast-activating factor in the mouse. Proc Natl Acad Sci USA. 1984;81:2181-5.

131. Gowen M, Wood DD, Ihrie EJ, McGuire MK, Russell RG. An interleukin 1 like factor stimulates bone resorption in vitro. Nature. 1983;306:378-80.

132. Kanzaki H, Chiba M, Shimizu Y, Mitani H. Periodontal ligament cells under mechanical stress induce osteoclastogenesis by receptor activator of nuclear factor kappaB ligand up-regulation via prostaglandin E2 synthesis. J Bone Miner Res. 2002;17:210-20.

133. Yamaguchi M, Aihara N, Kojima T, Kasai K. RANKL increase in compressed periodontal ligament cells from root resorption. J Dent Res. 2006;85:751-6.

134. Tatakis DN. Interleukin-1 and bone metabolism: a review. J Periodontol. 1993;64:416-31.

135. Komine M, Kukita A, Kukita T, Ogata Y, Hotokebuchi T, Kohashi O. Tumor necrosis factor-alpha cooperates with receptor activator of nuclear factor kappaB ligand in generation of osteoclasts in stromal cell-depleted rat bone marrow cell culture. Bone. 2001;28:474-83.

136. Miyamoto T, Arai F, Ohneda O, Takagi K, Anderson DM, Suda T. An adherent condition is required for formation of multinuclear osteoclasts in the presence of macrophage colony-stimulating factor and receptor activator of nuclear factor kappa B ligand. Blood. 2000;96:4335-43.

137. Fisher LW, Torchia DA, Fohr B, Young MF, Fedarko NS. Flexible structures of SIBLING proteins, bone sialoprotein, and osteopontin. Biochem Biophys Res Commun. 2001;280:460-5.

138. Chellaiah M, Hruska K. Osteopontin stimulates gelsolin-associated phosphoinositide levels and phosphatidylinositol triphosphatehydroxyl kinase. Mol Biol Cell. 1996;7:743-53.

139. Stenbeck G, Horton MA. A new specialized cell-matrix interaction in actively resorbing osteoclasts. J Cell Sci. 2000;113:1577-87.

140. Rumpler M, Würger T, Roschger P, Zwettler E, Sturmlechner I, Altmann $P$, et al. Osteoclasts on bone and dentin in vitro: mechanism of trail formation and comparison of resorption behavior. Calcif Tissue Int. 2013;93:526-39

141. Geblinger D, Addadi L, Geiger B. Nano-topography sensing by osteoclasts. J Cell Sci. 2010;123:1503-10.

142. Blair HC, Teitelbaum SL, Ghiselli R, Gluck S. Osteoclastic bone resorption by a polarized vacuolar proton pump. Science. 1989;245:855-7.

143. Väänänen HK, Karhukorpi EK, Sundquist K, Wallmark B, Roininen I, Hentunen $T$, et al. Evidence for the presence of a proton pump of the vacuolar $\mathrm{H}(+)$-ATPase type in the ruffled borders of osteoclasts. J Cell Biol. 1990;111:1305-11.

144. Gowen M, Lazner F, Dodds R, Kapadia R, Feild J, Tavaria M, et al. Cathepsin $\mathrm{K}$ knockout mice develop osteopetrosis due to a deficit in matrix degradation but not demineralization. J Bone Miner Res. 1999;14:1654-63.

145. Casa MA, Faltin RM, Faltin K, Arana-Chavez VE. Root resorption on torqued human premolars shown by tartrate-resistant acid phosphatase histochemistry and transmission electron microscopy. Angle Orthod. 2006;76:1015-21. 
146. Sasaki T. Differentiation and functions of osteoclasts and odontoclasts in mineralized tissue resorption. Microsc Res Tech. 2003;61:483-95.

147. Brudvik P, Rygh P. The initial phase of orthodontic root resorption incident to local compression of the periodontal ligament. Eur J Orthod. 1993;15:249-63.

148. Heinrich J, Bsoul S, Barnes J, Woodruff K, Abboud S. CSF-1, RANKL and OPG regulate osteoclastogenesis during murine tooth eruption. Arch Oral Biol. 2005;50:897-908.

149. Rani CS, Macdougall M. Dental cells express factors that regulate bone resorption. Mol Cell Biol Res Commun. 2000;3:145-52.

150. Fukushima H, Kajiya H, Takada K, Okamoto F, Okabe K. Expression and role of RANKL in periodontal ligament cells during physiological rootresorption in human deciduous teeth. Eur J Oral Sci. 2003;111:346-52.

151. Zhang D, Yang YQ, Li XT, Fu MK. The expression of osteoprotegerin and the receptor activator of nuclear factor kappa B ligand in human periodontal ligament cells cultured with and without 1alpha,25-dihydroxyvitamin D3. Arch Oral Biol. 2004;49:71-6.

152. Low E, Zoellner H, Kharbanda OP, Darendeliler MA. Expression of mRNA for osteoprotegerin and receptor activator of nuclear factor kappa beta ligand (RANKL) during root resorption induced by the application of heavy orthodontic forces on rat molars. Am J Orthod Dentofacial Orthop. 2005;128:497-503.

153. da Silva $L A B$, Longo DL, Stuani MBS, de Queiroz AM, da Silva RAB, Nelson-Filho $P$, et al. Effect of root surface treatment with denusomab after delayed tooth replantation. Clin Oral Invest. 2021;25:1255-64.

154. Qian H, Ding Y, Wu Y, Li S. The effects of three modified Hank's balanced salt solutions on root resorption of late replanted teeth: a pilot study. J Craniomaxillofac Surg. 2018;46:808-14.

155. Nishimi M, Nakamuraa K, Hisada A, Endo K, Ushimura S, Yoshimura Y, et al. Effects of $\mathrm{N}$-acetylcysteine on root resorption after tooth replantation. Pediatr Dent J. 2020:30:72-9.

156. Yamamoto T, Kita M, Oseko F, Nakamura T, Imanishi J, Kanamura N. Cytokine production in human periodontal ligament cells stimulated with Porphyromonas gingivalis. J Periodont Res. 2006;41:554-9.

157. Bab IA, Sela MN, Ginsburg I, Dishon T. Inflammatory lesions and bone resorption induced in the rat periodontium by lipoteichoic acid of Streptococcus mutans. Inflammation. 1979;3:345-58.

158. Patel S, Mavridou AM, Lambrechts P, Saberi N. External cervical resorption-part 1: histopathology, distribution and presentation. Int Endod J. 2018:51:1205-23.

159. Garlet TP, Coelho U, Repeke CE, Silva JS, de Cunha FQ, Garlet GP. Differential expression of osteoblast and osteoclast chemmoatractants in compression and tension sides during orthodontic movement. Cytokine. 2008:42:330-5.

160. Davidovitch Z, Musich D, Doyle M. Hormonal effects on orthodontic tooth movement in cats—a pilot study. Am J Orthod. 1972:62:95-6.

161. Philbrick WM, Dreyer BE, Nakchbandi IA, Karaplis AC. Parathyroid hormone-related protein is required for tooth eruption. Proc Natl Acad Sci USA. 1998;95:11846-51.

162. Nakchbandi IA, Weir EE, Insogna KL, Philbrick WM, Broadus AE. Parathyroid hormone-related protein induces spontaneous osteoclast formation via a paracrine cascade. Proc Natl Acad Sci USA. 2000;97:7296-300.

163. Stashenko P, Yu SM, Wang CY. Kinetics of immune cell and bone resorptive responses to endodontic infections. J Endod. 1992;18:422-6.
164. Stashenko P, Jandinski JJ, Fujiyoshi P, Rynar J, Socransky SS. Tissue levels of bone resorptive cytokines in periodontal disease. J Periodontol. 1991:62:504-9.

165. Suda T, Nakamura I, Jimi E, Takahashi N. Regulation of osteoclast function. J Bone Miner Res. 1997:12:869-79.

166. Oka H, Miyauchi M, Sakamoto K, Moriwaki S, Niida S, Noguchi K, et al. PGE2 activates cementoclastogenesis by cementoblasts via EP4. J Dent Res. 2007;86:974-9.

167. Choi B-K, Moon S-Y, Cha J-H, Kim K-W, Yoo Y-J. Prostaglandin E(2) is a main mediator in receptor activator of nuclear factor-kappaB ligand-dependent osteoclastogenesis induced by Porphyromonas gingivalis, Treponema denticola, and Treponema socranskii. J Periodontol. 2005:76:813-20.

168. Datta HK, Manning P, Rathod H, McNeil CJ. Effect of calcitonin, elevated calcium and extracellular matrices on superoxide anion production by rat osteoclasts. Exp Physiol. 1995;80:713-9.

169. Egerton M, Needham M, Evans S, Millest A, Cerillo G, McPheat J, et al. Identification of multiple human calcitonin receptor isoforms: heterologous expression and pharmacological characterization. J Mol Endocrinol. 1995:14:179-89.

170. Pierce AM, Lindskog S. Early responses by osteoclasts in vivo and dentinoclasts in vitro to corticosteroids. J Submicrosc Cytol Pathol. 1989;21:501-8.

171. Haapasalo M, Endal U. Internal inflammatory root resorption: the unknown resorption of the tooth. Endod Topics. 2006;14:60-79.

172. Patel S, Kanagasingam S, Pitt FT. External cervical resorption: a review. J Endod. 2009:35:616-25.

173. Andersen M, Lund A, Andreasen JO, Andreasen FM. In vitro solubility of human pulp tissue in calcium hydroxide and sodium hypochlorite. Endod Dent Traumatol. 1992;8:104-8.

174. Chikazu D, Katagiri M, Ogasawara T, Ogata N, Shimoaka T, Takato T, et al. Regulation of osteoclast differentiation by fibroblast growth factor 2: stimulation of receptor activator of nuclear factor kappaB ligand/ osteoclast differentiation factor expression in osteoblasts and inhibition of macrophage colony-stimulating factor function in osteoclast precursors. J Bone Miner Res. 2001;16:2074-81.

175. Schmucker C, Motschall E, Antes G, Meerpohl JJ. Methods of evidence mapping. A systematic review. Bundesgesundheitsblatt Gesundheitsforschung Gesundheitsschutz. 2013;56:1390-7.

176. Levac D, Colquhoun H, O'Brien KK. Scoping studies: advancing the methodology. Implement Sci. 2010;5:69-79.

177. Arksey H, O'Malley L. Scoping studies: towards a methodological framework. Int J Soc Res Methodol. 2005;8:19-32.

178. Armstrong R, Hall BJ, Doyle J, Waters E. Cochrane update. "Scoping the scope" of a cochrane review. J Public Health. 2011;33:147-50.

179. Sae-Lim V, Wang CY, Choi GW, Trope M. The effect of systemic tetracycline on resorption of dried replanted dogs'teeth. Endod Dent Traumatol. 1998;14:127-32.

\section{Publisher's Note}

Springer Nature remains neutral with regard to jurisdictional claims in published maps and institutional affiliations.

Ready to submit your research? Choose BMC and benefit from

- fast, convenient online submission

- thorough peer review by experienced researchers in your field

- rapid publication on acceptance

- support for research data, including large and complex data types

- gold Open Access which fosters wider collaboration and increased citations

- maximum visibility for your research: over 100M website views per year

At BMC, research is always in progress.

Learn more biomedcentral.com/submissions 